\title{
Pró-Saúde - Odontologia/UNISC: experiências e contribuições na formação profissional
}

\author{
Micheli Chabat da Silva*, Beatriz Baldo Marques**, Magda de Sousa Reis***, Renita Baldo \\ Moraes**** \\ * Acadêmica do curso de Odontologia da Universidade de Santa Cruz \\ do Sul - RS \\ ** Professora Coordenadora do PRÓ-SAÚDE I - Odontologia/UNISC \\ *** Professora Coordenadora do PRÓ-SAÚDE I - Odontologia/UNISC \\ ***** Professora Coordenadora do PRÓ-SAÚDE I - Odontologia/UNISC
}

\section{RESUMO}

O objetivo deste trabalho foi realizar uma pesquisa com os acadêmicos do curso de Odontologia da Universidade de Santa Cruz do Sul (UNISC), que desenvolveram alguma atividade no bairro, através do PRÓ-SAÚDE, onde foi questionado se esta atividade contribuiu para sua formação profissional. A educação superior deve estar atrelada à realidade da população e a responsabilidade das ações de Promoção de Saúde deve ser integrada entre os indivíduos, comunidades, profissionais de saúde e instituições que prestam serviço de saúde. É de fundamental importância essa integração com os serviços, pois desta forma se cria habilidades para trabalhar em democracia, para o desenvolvimento de uma visão crítica e de competências culturais. Os dados foram coletados a partir de 51 instrumentos de pesquisa aplicados. Dos acadêmicos entrevistados, $99 \%$ responderam que a motivação do PRÓ-SAÚDE trouxe benefício para a sua vida. Destes, $53 \%$ apontou dimensão profissional como o benefício mais significativo, seguidos de $35,2 \%$ em termos de dimensão social, e 11,8\% de destaque para a dimensão pessoal. Outro dado levantado na entrevista com os acadêmicos foi de que $60,9 \%$ pretendem iniciar sua vida profissional preferencialmente na rede pública, $25,4 \%$ prioritariamente em consultório ou clínica privada e talvez rede pública, 11,8\% somente em consultório ou clínica privada, e 1,9\% somente na rede pública. Desta forma, reafirma-se a importância do PRÓ-SAÚDE para a formação de profissionais capacitados a trabalharem na rede pública.

\section{DESCRITORES}

Odontologia. Odontologia Preventiva. Educação em Odontologia. Saúde. Odontologia Comunitária.

$\Delta$ s práticas de saúde através de ações curativas de caráter individual mostram-se cada vez mais ineficazes para solução de problemas que afetam a cavidade bucal, como a cárie dentária e a doença periodontal. Formar um profissional apto a perceber suas limitações, desafios e potencialidades frente às reais necessidades da população, é o que tem motivado setores responsáveis pela formação dos profissionais de saúde bucal, Ministério da Educação, Ministério da Saúde e as instituições de educação superior, a não poupar esforços e determinar Diretrizes Curriculares Nacionais (DCNs) para os Cursos de Graduação em Odontologia. Toda essa mudança é baseada na motivação e convicção de que o Sistema Único de Saúde (SUS) necessita de profissionais conscientes e motivados em seus postos de trabalho.

As DCNs instituem como perfil do egresso do curso de Odontologia, um profissional generalista, humanista, crítico e reflexivo para atuar em todos os níveis de atenção à saúde, com base no rigor técnico e científico. Este profissional deverá estar capacitado a realizar atividades referentes à saúde bucal da população pautado em princípios éticos, legais e na compreensão da realidade social, cultural e econômica do seu meio, dirigindo sua atuação para a transformação da realidade em benefício da realidade.

O currículo do curso de Odontologia da UNISC está organizado de tal maneira que busca a formação do acadêmico de forma integral, estimulando o com- 
prometimento com os problemas enfrentados pela sociedade, e oportunizando ao acadêmico uma reflexão sobre seu papel transformador frente à sociedade. Para intensificar esta formação, após concorrer ao edital do PRO-SAUDE I, a UNISC iniciou suas atividades odontológicas, no bairro Santa Vitória, no ano de 2010, quando os acadêmicos se inseriram no programa através de disciplinas, estágios curriculares e projetos de extensão.

O programa tem o objetivo de ampliar a integração desde os primeiros semestres do curso, entre acadêmicos, professores da universidade e com os profissionais que integram a rede de serviços de saúde do município de Santa Cruz do Sul, mais especificamente com a equipe de profissionais das Estratégias de Saúde da Família.

Este trabalho verificou, portanto, o impacto que o Programa Nacional de Reorientação da Formação Profissional em Saúde teve sobre os acadêmicos do curso de Odontologia da Universidade de Santa Cruz do Sul.

\section{MATERIAIS E MÉTODOS}

O estudo realizado foi quantitativo observacional transversal descritivo, com objetivo de investigar e descrever as experiências e contribuições do PRÓSAUDE na formação profissional. Os sujeitos da pesquisa foram os estudantes do curso de Odontologia, da Universidade de Santa Cruz do Sul inseridos nas atividades desenvolvidas no bairro Santa Vitória, onde se programou ações do PRÓ-SAÚDE.

Os dados foram coletados a partir de um questionário com 13 questões abertas e fechadas. Estas abordavam o semestre em que os acadêmicos estavam matriculados, o número de vezes que atuou no programa, o tipo de atividade desenvolvida e se havia ouvido falar no programa antes de iniciar suas atividades. Também foram abordadas questões referentes às DCNs, percepção do acadêmico em relação às atividades realizadas no Programa, dimensão que o acadêmico sentiu maior benefício.

Participaram da pesquisa 51 acadêmicos, regularmente matriculados no curso de Odontologia, da UNISC de Santa Cruz do Sul no RS. Estes realizaram atividades através de disciplinas, estágios curriculares ou através de projetos de extensão. A participação da pesquisa foi voluntária, com a obtenção do Termo de Consentimento Livre e Esclarecido de cada sujeito, sem identificação revelada dos participantes.

Foi realizado anteriormente ao início da coleta de dados, o projeto piloto onde o instrumento de pes- quisa foi aplicado a 10 participantes para avaliar se as perguntas foram elaboradas adequadamente. O retorno do projeto piloto foi positivo, com todos participantes conseguindo interpretar de forma correta o questionário.

\section{RESULTADOS E DISCUSSÃO}

$\mathrm{O}$ instrumento de pesquisa, respondido por 51 acadêmicos regularmente matriculados no $7^{\circ}$ e $9^{\circ}$ semestre do curso de Odontologia da UNISC. A idade dos entrevistados variou de 20 anos a 34 anos. Dos participantes, $35,2 \%$ foram realizar atividades no bairro através do PRÓ-SAÚDE menos de cinco vezes; $27,6 \%$ de seis a nove vezes e $37,2 \%$ dez vezes ou mais.

As atividades desenvolvidas ocorreram em sua maioria através de disciplinas curriculares (Periodontia e Cirurgia), seguida dos Estágios Supervisionados (Estágio Supervisionado Odontopediátrico, e Estágio Supervisionado II) e Projetos de Extensão (Atenção à Saúde da Criança e do Adolescente). Destas atividades, a maior parte deu-se através do atendimento clínico à população, seguido por visitas domiciliares $\mathrm{e}$ trabalhos de educação em saúde diretamente com a comunidade.

Os acadêmicos foram questionados se antes de desenvolverem as atividades através do PRÓ-SAÚDE tinham conhecimento do programa. A maioria $(84,4 \%)$ já havia ouvido falar do mesmo na Universidade, tendo sido orientado quanto ao local, o tipo de atividade que seria realizado, o público alvo e os objetivos do programa, e 15,6\% nunca haviam ouvido falar do PRÓ-SAÚDE antes de iniciarem suas atividades.

Quando questionados sobre seu conhecimento acerca das Diretrizes Curriculares Nacionais (DCNs): $54,9 \%$ conhecem muito pouco, $35,3 \%$ não conhecem e apenas 9,8\% conhecem. Quanto à relação entre as Diretrizes Curriculares Nacionais e o Programa de Reorientação da formação Profissional: $84,4 \%$ não souberam dizer se há relação e 15,6\% afirmaram haver relação entre eles. Quando questionados sobre qual a relação existente, os acadêmicos citaram o envolvimento com o ensino, comunidade e extensão, e a promoção de saúde. Além disso, houve também o relato da busca por uma aprendizagem interdisciplinar, formação continuada, formação de novos profissionais comprometidos com a saúde das pessoas, não somente bucal, mas a saúde geral da comunidade.

Nas entrevistas, $80,4 \%$ responderam que sentiram diferença em atender no bairro, frente ao Programa enquanto 19,6\% (Gráfico 1) não perceberam diferen- 
ça destas atividades quando comparadas ao atendimento na clínica de Odontologia da Universidade. Para os que perceberam a diferença as mais citadas foram: complexidade dos casos encontrados na comunidade, classe econômica, diferença de instrução sobre saúde dos pacientes, entre outros.

Em relação à aproximação do acadêmico com os demais profissionais de saúde, $54,9 \%$ sentiram tal aproximação com os profissionais enquanto 45,1\% não perceberam sua presença. Esses profissionais estão vinculados com: agentes comunitários de Saúde, enfermagem, medicina, nutrição e fisioterapia.

As condições de trabalho como infraestrutura, equipamentos e materiais utilizados foram também avaliados e 27,4\% dos acadêmicos responderam que local de atendimento das ações do PRÓ-SAÚDE é semelhante ao serviço público, enquanto $72,6 \%$ responderam que não vêem semelhança. As principais diferenças apontadas pelos acadêmicos, é que o tempo de atendimento para acolhimento e vínculo com os pacientes é maior no PRÓ SAÚDE e os materiais utilizados são superiores aos que encontramos nos serviços públicos de saúde.

Após a conclusão do curso, 60,9\% (Gráfico 2) dos participantes pretendem iniciar com emprego preferencialmente na rede pública e depois trabalhar em consultório particular ou clínica privada, 25,4\% pretendem iniciar prioritariamente em consultório particular, ou clínica privada e talvez na rede pública, $11,7 \%$ pretendem iniciar sua vida profissional somente em consultório particular ou clínica privada e 1,9\% pretendem trabalhar somente na rede pública.

Os acadêmicos foram questionados se o desenvolvimento dessa atividade trouxe algum benefício para a vida, 98,1\% responderam sim, sendo a dimensão profissional o benefício mais percebido entre os acadêmicos, seguindo pelo benefício social (através do convívio com pessoas de realidade diferente) e apenas $1,9 \%$ responderam que não (Gráfico 3 ).

De acordo com a pesquisa realizada, o Programa Nacional de Reorientação da Formação Profissional em Saúde possibilita uma forma nova de atuação para os acadêmicos do curso de Odontologia, sendo um ponto positivo a divulgação e esclarecimento da Universidade em relação a esse Programa. Desta forma, a maioria dos acadêmicos ao iniciar suas atividades junto à comunidade já tinha de forma clara qual seria a população atingida, as características da comunidade em que trabalhariam, e os objetivos do Programa. Um grande número de acadêmicos percebeu diferenças em atender nos bairros quando comparado à clí-

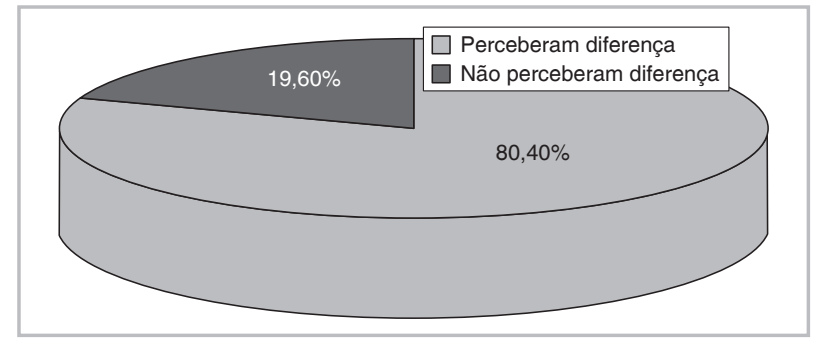

Gráfico 1 - Diferença de atendimento percebida pelos acadêmicos na clínica de Odontologia/UNISC e no bairro onde se desenvolve ações do Pró-Saúde - Santa Cruz do Sul / RS

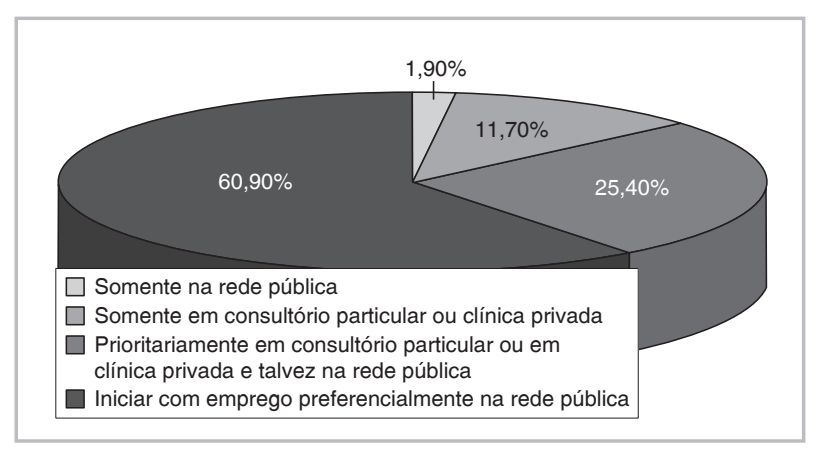

Gráfico 2 - Interesse de atuação dos acadêmicos após a conclusão da graduação. Santa Cruz do Sul / RS

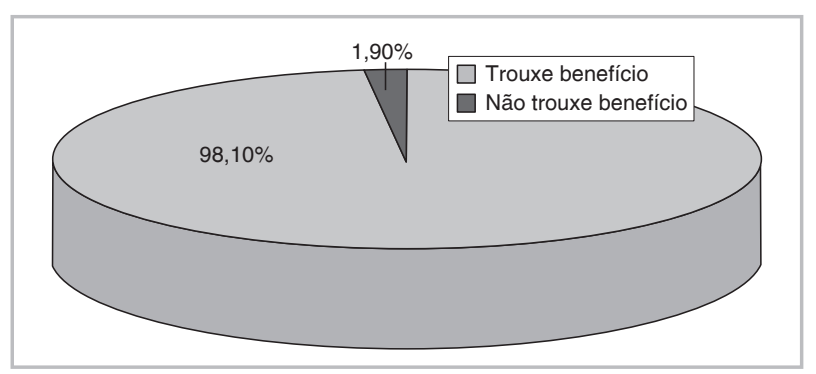

Gráfico 3 - Benefícios percebidos pelos acadêmicos do Curso de Odontologia na atuação junto ao Pró-Saúde Santa Cruz do Sul / RS

nica da Universidade, mostrando desta forma que apresentam um olhar voltado para uma Odontologia comunitária, onde se tem como ênfase a atenção básica, mas não se deixa de lado os conhecimentos técnicos e científicos.

O número de acadêmicos que pretendem iniciar suas atividades profissionais preferencialmente na rede pública vem crescendo com o passar dos anos. Esse interesse, reflexo do mercado de trabalho e de um currículo voltado para a realidade em que muitos profissionais enfrentam após a conclusão da graduação, faz com que os acadêmicos busquem informações para atuarem mais ligados com a comunidade, 
com uma formação profissional de qualidade. Neste sentido, o PRÓ-SAÚDE vem contribuindo significativamente no novo olhar do acadêmico em suas atuações na comunidade.

Em relação aos benefícios trazidos pela realização de atividades através do PRÓ-SAÚDE, as respostas foram favoráveis, comprovando o benefício para o acadêmico, que possui a oportunidade de atuar direto com a comunidade, de forma integral, em disciplinas, estágios e projetos. Neste momento também se pode desenvolver poder transformador enquanto acadêmicos que se envolvem em ações sociais, não só com a saúde bucal, mas sim a saúde geral e bem estar do paciente, suprindo desta forma as necessidades da população, com escuta adequada. As visitas domiciliares possibilitam conhecer a realidade das famílias atendidas, conseguindo desta forma ampliar a visão geral e desenvolver as ações da melhor maneira possível. A comunidade é a principal beneficiada com o Programa, pois futuramente esses acadêmicos serão os profissionais da rede, e conseqüentemente estarão capacitados a trabalhar nesse espaço, sabendo enfrentar as dificuldades encontradas e anseios vividos pela comunidade.

\section{CONCLUSÃO}

Ressalta-se a importância deste trabalho, pois desta maneira os acadêmicos podem perceber que a saúde pública vem crescendo a cada ano, e precisamos de profissionais capacitados para atuarem nesta área. O Programa Nacional de Reorientação da Formação Profissional teve uma adesão entre os acadêmicos, e a devida importância, sendo considerada uma experiência válida, que contribuiu de forma significante para o seu crescimento profissional e pessoal.

\section{ABSTRACT}

Pro-Health - Dentistry/UNISC: experiences and contributions to professional training

The purpose of this paper was to conduct a survey among dentistry students of the Universidade de Santa Cruz do Sul (UNISC) who develop any sort of activity within the PRO-HEALTH (PRÓ-SAÚDE) program. The question asked was if this activity contributed to his/her professional training. Higher education must be tied to the reality of the population, and the responsability of health promotion actions must be integrated among persons, communities, health professionals and institutions that provide health services. This integration with health services is very important, because it builds the skills needed to work democratically, and to develop a critical vision and cultural capabilities. The data was collected through 51 questionaires; $99 \%$ of the students interviewed answered that their PRO-HEALTH activities brought benefits to their life; $53 \%$ of these students pointed out the professional benefits as the most significant plus factor; $35.2 \%$ answered that the most significant gains were the social benefits; and $11.8 \%$ highlighted the personal benefits as most significant. Among the students interviewed, $60.9 \%$ intend to start their professional life preferentially in public service, $25.4 \%$ give priority to working in a private office or clinic or perhaps public service, $11.8 \%$ intend to work only in a private office or clinic, and $1.9 \%$ intend to work only in public services. Accordingly, we can see the importance of PRO-HEALTH in training professionals skilled to work in public service.

\section{DESCRIPTORS}

Dentistry. Preventive Dentistry. Dentistry Education. Health. Community Dentistry. -

\section{REFERÊNCIAS BIBLIOGRÁFICAS}

1. BRASIL. Ministério da Saúde. Conselho Nacional de Saúde. $3^{\circ}$ Conferência Nacional de Saúde: Acesso e qualidade superando a exclusão social - relatório Final/ Ministério da Saúde, Conselho Nacional de Saúde - Brasília, 2004.

2. BRASIL. Ministério da Saúde. Ministério da Educação. Programa Nacional de Reorientação da Formação Profissional em Saúde - Pró-Saúde: objetivos, implementação e desenvolvimento potencial/Ministério da Saúde, Ministério da Educação - Brasília: Ministério da Saúde, 2007.

3. BRASIL. Resolução CNE/CES 3, de 19 de fevereiro de 2002: Institui Diretrizes Curriculares Nacionais do Curso de Graduação em Odontologia. Conselho Nacional de Educação/Câmera de Educação Superior - Brasília: Conselho Nacional de Educação, 2002. p. 1-5, passim.

4. HEIRO, F. M. C. et al. A formação do Cirurgião Dentista no Brasil: contribuições de estudos para a prática da profissão. Porto Alegre, v.57, n.1, p. 99-106,2009.

5. MORITA, M. C. et al. Visita domiciliar:oportunidade de aprendizagem na graduação em Odontologia. Revista de Odontologia da UNESP, Araraquara, 2010. 39(2): 75-79.

Recebido em 07/07/2011 Aceito em 25/07/2011 